\title{
CAVITATION EROSION RESISTANCE OF GX40CRNISI 25 - 20 CAST STAINLESS STEEL
}

\author{
${ }^{1}$ Daniela COSMA (ALEXA), ${ }^{2}$ Ion MITELEA, ${ }^{2}$ llare BORDEASU, ${ }^{1}$ Vasile ALEXA, \\ ${ }^{2}$ Corneliu Marius CRACIUNESCU \\ ${ }^{1}$ University Politehnica Timisoara, Faculty of Engineering, Hunedoara, Romania, \\ daniela.alexa@fih.upt.ro, vasile.alexa@fih.upt.ro \\ ${ }^{2}$ University Politehnica Timisoara, Faculty of Mechanical Engineering, Timisoara, Romania, \\ ion.mitelea@upt.ro, ilare.bordeasu@upt.ro, corneliu.craciunescu@upt.ro
}

https://doi.org/10.37904/metal.2021.4136

\begin{abstract}
Cavity erosion is a complex and localized phenomenon involving mechanical, chemical and metallurgical parameters. The development of new materials depends on understanding the relationship between microstructure and cavity erosion. This paper investigates the role played by the chemical composition and microstructure on the erosion behavior through the cavity of high alloy steel $25 \mathrm{Cr}-20 \mathrm{Ni}$ cast in parts. The cavitation tests were performed using an ultrasonic vibrator at a frequency of $20 \mathrm{kHz}$ and amplitude oscillation amplitude of $50 \mu \mathrm{m}$. The surface of the eroded samples was examined under an optical microscope and an electron scanning microscope. It's performance is compared to that of cast martensitic stainless steel, GX10Cr13
\end{abstract}

Keywords: high $\mathrm{Cr}-\mathrm{Ni}$ cast stainless steel, cavitation erosion, microstructure

\section{INTRODUCTION}

Stainless steels are usually classified as "corrosion-resistant" when used in aqueous and vapor environments below $650^{\circ} \mathrm{C}$ and as "heat-resistant" when used above this temperature [1]. The usual distinction between classes of heat and corrosion resistant cast steels lies in the carbon content. For a stainless steel cast to work well in a corrosive environment, the carbon content must be reduced. Brands of heat-resistant steels have high carbon contents to improve their resistance to high temperatures [2]. The chemical composition and microstructural differences between the rolled and cast versions of stainless steels can affect their performance. Although some brands of stainless steels cast in parts can be hardened by applying the heat treatment of hardening for solution followed by aging by tempering, the mechanical properties of most of these alloys are based on their chemical composition [3].

Stainless steels cast in parts generally have a corrosion resistance similar to that of laminated equivalents, but may become less resistant to corrosion by cavity erosion due to localized contamination, micro segregation or lack of homogeneity [2]. For example, the quality of the mold can cause superficial compositional changes that influence performance, and the uptake of carbon by mold release agents can affect the resistance to corrosion and erosion by cavitation [3].

Chromium and nickel are the main alloying elements that determine the structure, mechanical properties, corrosion resistance and heat resistance of stainless-steel castings. Increasing the carbon content in these alloys improves mechanical strength at high temperatures and creep resistance but reduces ductility. In contrast, carbon can be harmful to corrosion resistance when combined with chromium to form chromium carbides along grain boundaries [4]. This reduces the chromium adjacent to the grain boundary (sensitization) and can lead to corrosion of chromium-depleted areas (intergranular corrosion). The additions of titanium, niobium and tantalum are preferably combined with carbon and nitrogen to prevent sensitization and eliminate 
susceptibility to intergranular corrosion. The addition of nitrogen in austenitic stainless steels improves the resistance to pitting and delays the kinetics of sigma phase formation [5,6]. The presence of silicon as an alloying element in stainless steels cast in parts increases the fluidity when casting and thus improves the castability. As the carbon plus silicon content increases, partial eutectic solidification improves the castability and properties of the castings. Silicon is generally limited to $1.5 \%$ in castings intended for operation above $815^{\circ} \mathrm{C}$, as it lowers the creep and breaking strength properties at high temperatures.

In the present study, the mechanism of wear of high alloy steel with emphasis on its applicability in environments that cause cavitation stresses was investigated.

\section{EXPERIMENTAL PROCEDURES}

From cast steel bars, GX40CrNiSi 25-20, (1.4848): EN 10295 having the chemical composition (in wt\%): $0.38 \mathrm{C}, 25.20 \mathrm{Cr}, 20.8 \mathrm{Ni}, 1.62 \mathrm{Si}, 1.49 \mathrm{Mn}, 0.34 \mathrm{Mo}, 0.031 \mathrm{P}, 0.027 \mathrm{~S}$ cavitation tests were performed.

As standard material was used cast steel, GX10Cr13 (in wt\%: $0.11 \mathrm{C}, 12.78 \mathrm{Cr}, 1,054 \mathrm{Ni}$ ) which is intended for the execution of engineering components required, especially in cavitation environments. The cavitation tests were conducted on a vibrating device with piezoceramic crystals (Figure 1) made in accordance with the requirements of ASTM G32-2010 [5] (vibration frequency $=20000 \pm 1 \% \mathrm{~Hz}$, double vibration amplitude $=50$ $\mu \mathrm{m}$, temperature distilled water $=22 \pm 1{ }^{\circ} \mathrm{C}$, generator power $=500 \mathrm{~W}$ ). The cavitation research was carried out on sets of 3 samples from each steel brand. The total duration of the test of each sample was 165 minutes, this being divided into 12 periods (one of 5 minutes and 10 minutes, respectively, and the next 10 periods of 15 minutes each). At the end of each test period, the sample was cleaned in acetone, air dried and weighed with an analytical balance having a sensitivity of $10^{-5} \mathrm{~g}$.

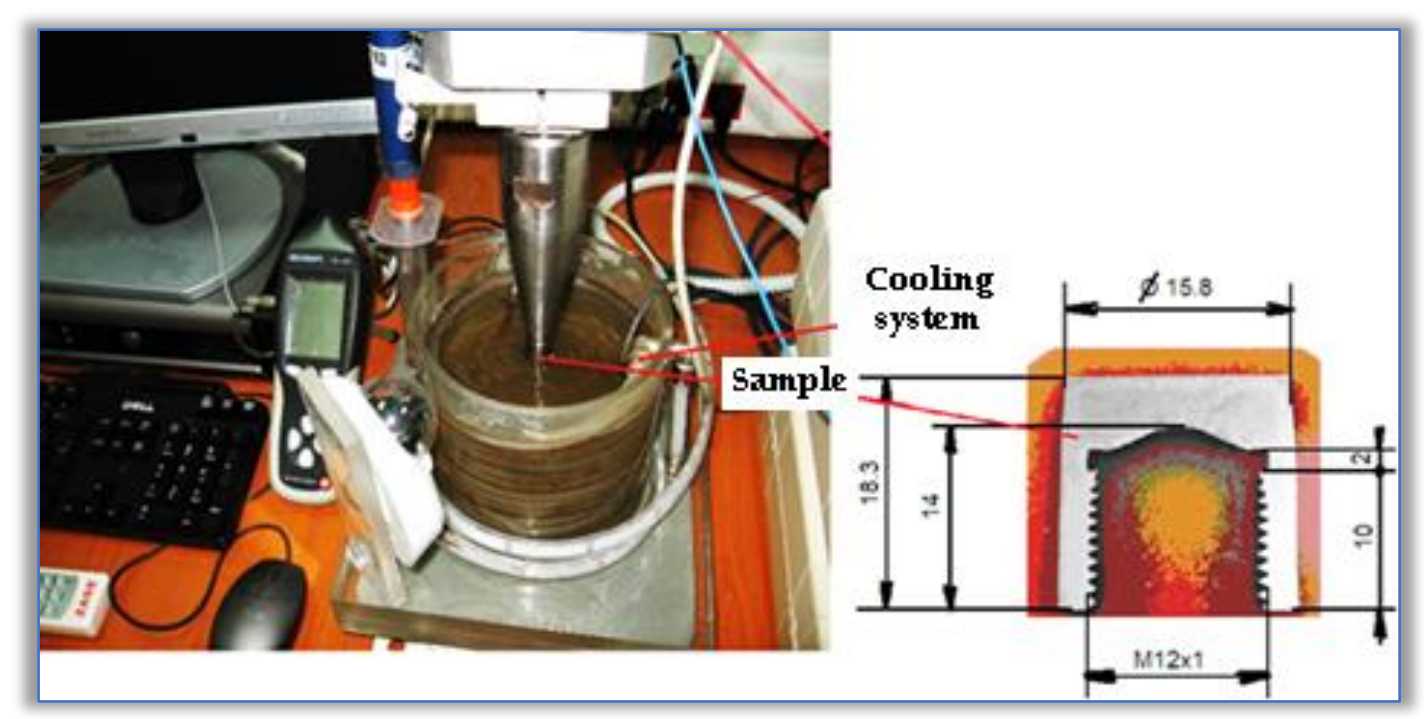

Figure 1 Image of the experimental stand and a section through the cavitation test

\section{EXPERIMENTAL RESULTS EVALUATION}

\subsection{Cavitation curves}

Cavitation tests were performed on sets of three samples, measuring the average cumulative mass losses and based on them were calculated the values of the average depth of penetration of erosion, cumulative, MDE, respectively, the rate of penetration of MDER erosion. 
$\mathrm{MDE}_{\mathrm{i}}=\sum_{\mathrm{i}=1}^{12} \Delta \mathrm{MDE}_{\mathrm{i}}=\frac{4 \cdot \mathrm{m}_{\mathrm{i}}}{\rho \cdot \pi \cdot \mathrm{d}_{\mathrm{p}}^{2}}[\mathrm{~mm}]$

$\operatorname{MDER}_{\mathrm{i}}=\frac{\Delta \mathrm{MDEi}}{\Delta \mathrm{ti}}$

where: $\mathrm{i}$ - represents the testing period;

$m_{i}-$ is the material mass, lost through erosion, in the period $i$, in grams;

$\rho$ - material density, in grams $/ \mathrm{mm}^{3}$;

$\Delta \mathrm{t}_{\mathrm{i}}$ - cavitation duration corresponding to period "i" (5 minutes, 10 minutes or 15 minutes);

$d_{p}-$ probe surface diameter, subjected to cavitation $\left(d_{p}=15.8 \mathrm{~mm}\right)$;

$\Delta \mathrm{MDE}_{\mathrm{i}}$ - the value of the average depth of erosion penetration, achieved by cavitation during the period $\Delta \mathrm{t}_{\mathrm{i}}$.

In Figure 2 and Figure 3 are shown the characteristic curves of cavitation erosion, which indicate the variation of the parameters MDE and MDER with the duration of the cavitation attack.



Figure 2 The evolution of the average erosion depth with the duration of the cavity attack

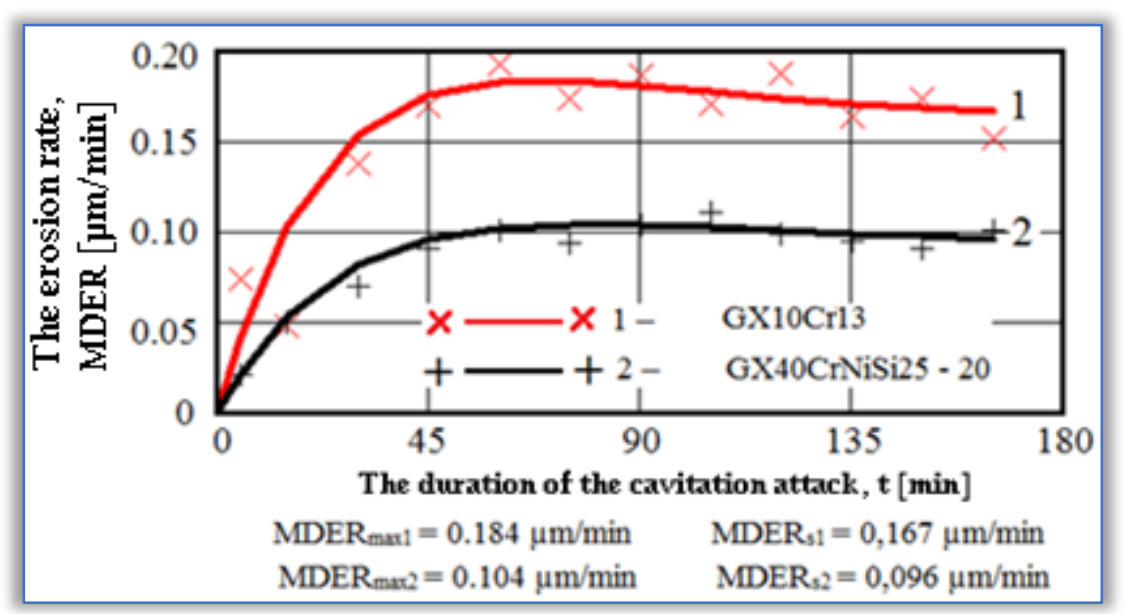

Figure 3 The evolution of the average erosion depth with the duration of the cavity attack 
From these graphs it can be noticed that the GX40CrNiSi25-20 steel has a value of the average erosion penetration depth, MDE, after 165 min. cavitation test of approx. 1.8 times smaller than that of GX10Cr13 steel. At the same time, the erosion rate during the stabilization period, MDERs of this steel decreases by approx. 1.7 times. The dispersion of the experimental values of the erosion rate (Figure 2), compared to the mediation curves, is slightly smaller for the GX10 $\mathrm{Cr} 13$ steel. Although it can be appreciated that both cast steels have a good behavior in cavitation erosion, the appearance of the curves being similar, still the steel with higher alloying degree ensures a higher resistance to degradation by this phenomenon.

\subsection{Microscopical examinations}

Using a Canon Power Shot S X 200 IS camera, images of the samples surfaces were taken after each period of cavitation attack to follow the evolution in time of the erosion phenomenon (Figure 4). Their analysis confirms that in the first 30 minutes of testing, the surface of the samples is not significantly affected, after which there is a continuous increase in the density of material pinches and their depth with the attack time. The cavity surface is due to the dendritic casting structure, characterized by micro segregations of the alloying elements.

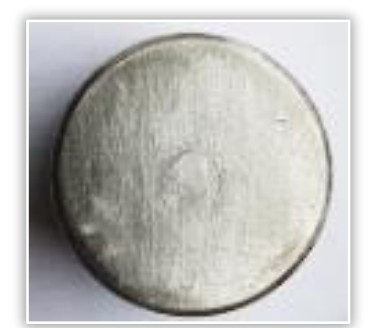

$0 \min$

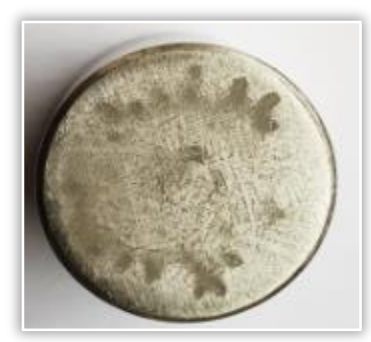

$45 \mathrm{~min}$

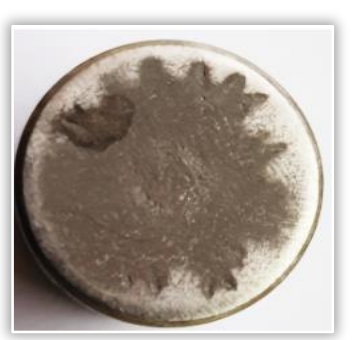

$105 \min$

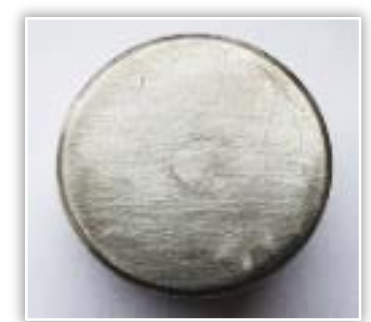

$5 \min$

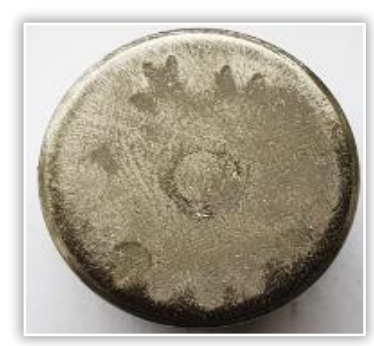

$60 \min$

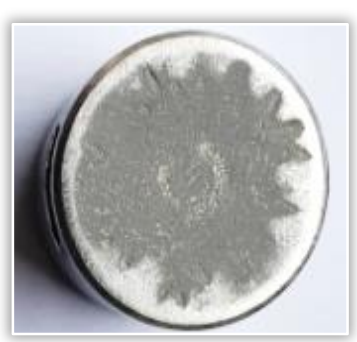

$120 \mathrm{~min}$

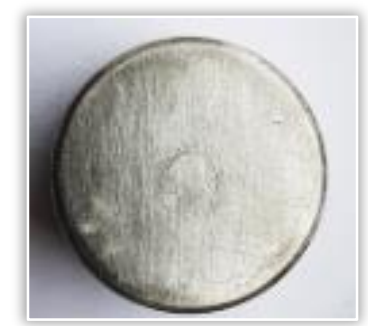

$15 \min$

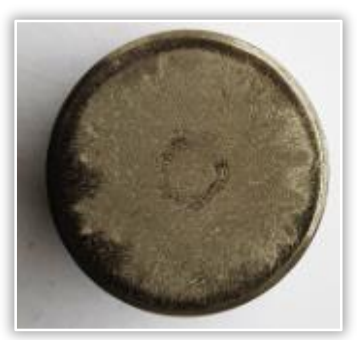

$75 \min$

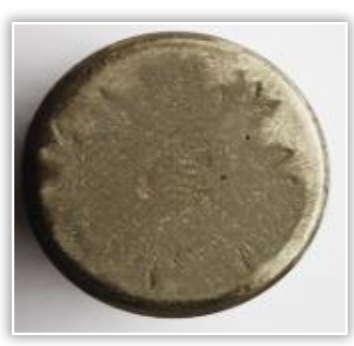

$135 \min$

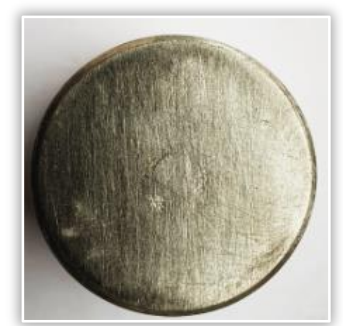

$30 \min$

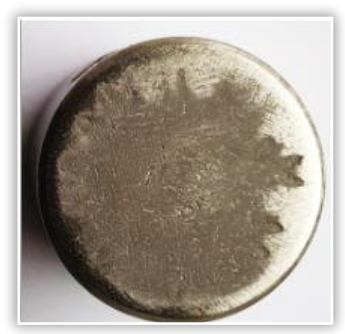

$90 \min$

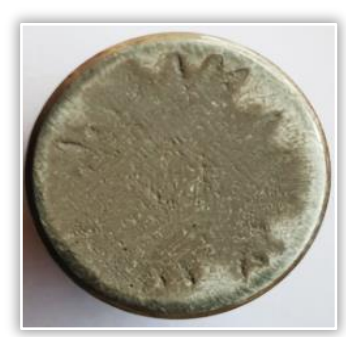

$150 \min$

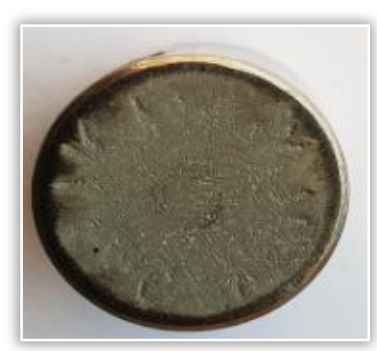

$165 \mathrm{~min}$

Figure 4 Macrographic image of the sample surface following the cavity attack 
Investigation under electric scanning microscope of the topography of tested surfaces on cavitation for 165 min. highlights the presence of pinches in the area of the matrix interface - carbides and matrix - phase $\sigma$ (Figures $\mathbf{5} \mathbf{a}, \mathbf{b}$ ). The areas of material left after the expulsion of carbides and the $\sigma$ phase have the form of microcracks with high stress concentrators that favor the development of microcracks.

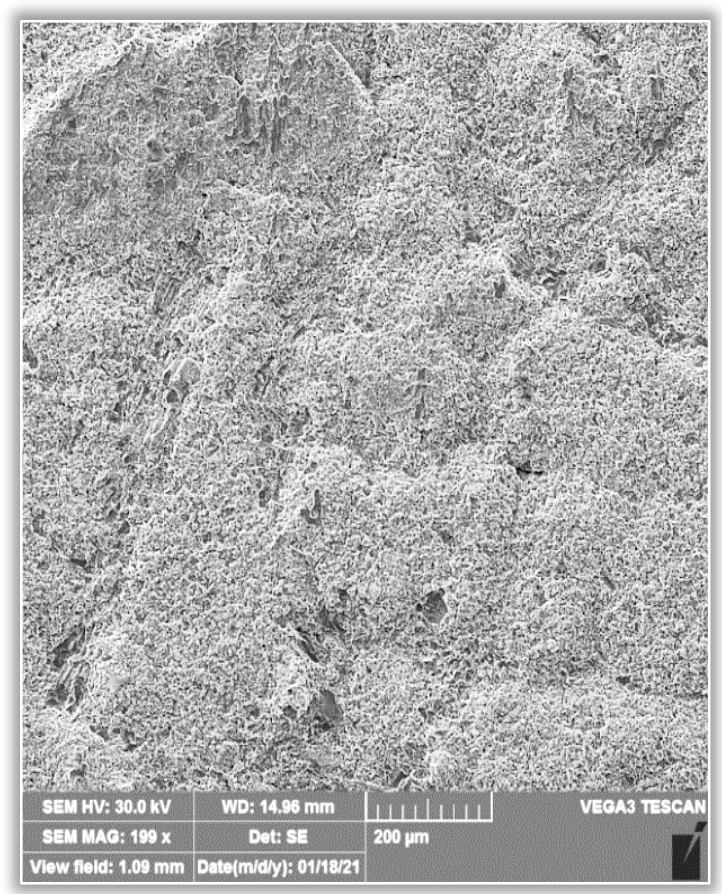

(a)

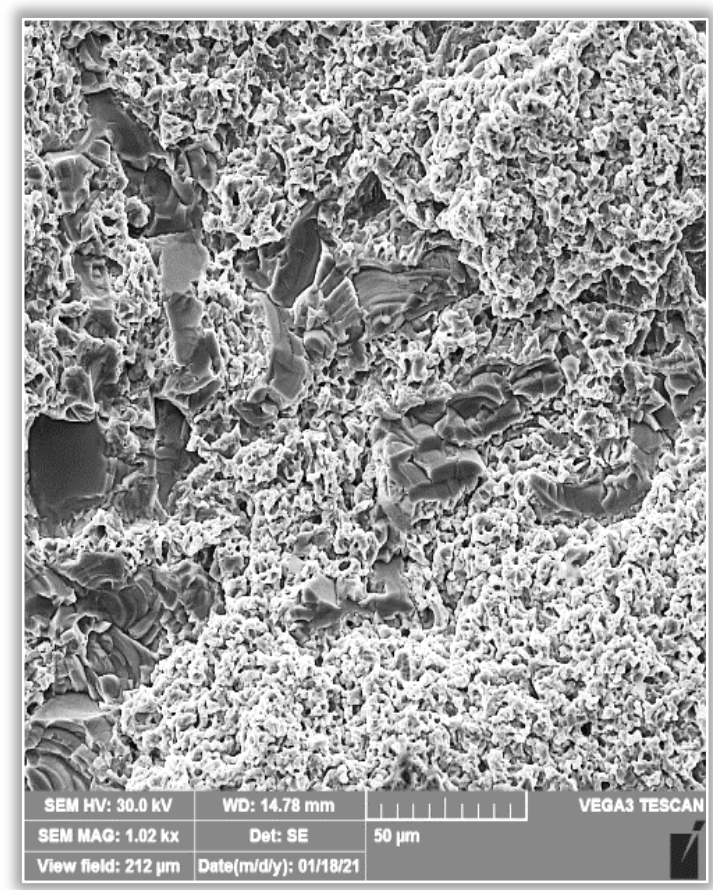

(b)

Figure 5 SEM image of the eroded surface after 165 minutes of cavitational attack:

$a-$ pinches of material, $\times 200 ; b-$ coalescence of microcracks and formation of microcracks, $\times 1000$

Optical microscopy of the longitudinal sections by samples tested in cavitation for 165 min. (Figure 6) shows that the expulsion of chemical combinations favors the degradation of the metal matrix. Although the mechanical strength of the martensite microstructure in steel with $13 \mathrm{wt} \% \mathrm{Cr}$ and $1 \mathrm{wt} \% \mathrm{Ni}$ considered as a standard is higher than that of an austenitic microstructure in steel with $25 \mathrm{wt} \% \mathrm{Cr}$ and $20 \mathrm{wt} \% \mathrm{Ni}$, the depth of erosion penetration is lower at the latter.

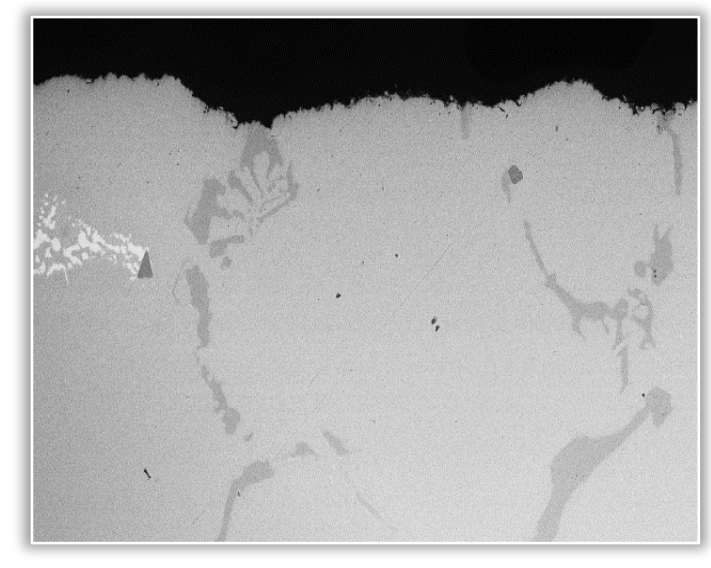

(a)

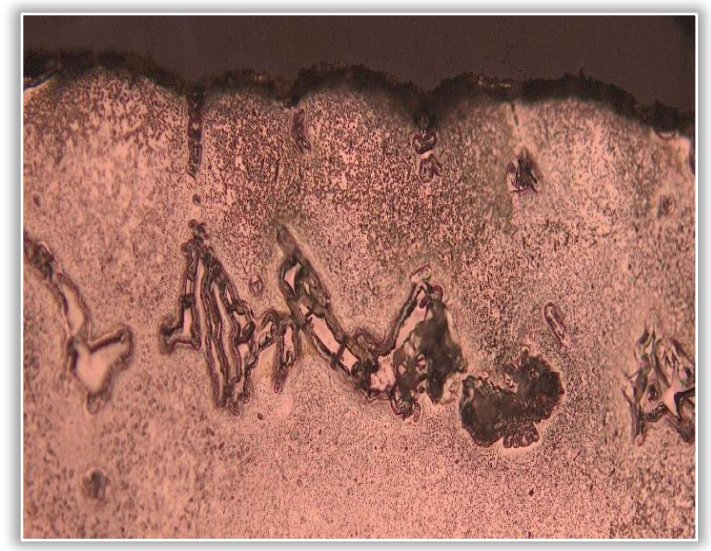

(b)

Figure 6 SEM image of a longitudinal section through a sample tested in cavitation for 165 min.: $a-x 200$, not chemically attacked; $b-x 200, V_{2} A$ chemical attack 


\section{CONCLUSION}

Compared to the GX10Cr13 standard steel, the GX40CrNISi25-20 analysed steel ensures an increase in cavitation resistance of about 1.8 times after the maximum value of the average cumulative erosion depth, (MDE curve (t)), respectively of about 1.7 times after the values stabilizes the erosion rate parameter, MDER.

The deterioration of the surface caused by the exposure to cavitation is initiated at the limits between the phases, followed by the removal of the $\sigma$ phase and the carbides, and subsequently the attack of the austenite matrix occurs.

\section{REFERENCES}

[1] ABBASI, M., VAHDATNIA, M., NAVAEI, A.: Solidification microstructure of HK heat resistant steel. International Journal of Metalcasting. 2015, Vol. 9, Issue 4, pp 19-26.

[2] HARO, S., LOPEZ, D., WONG, A., MARTINEZ, L., VELASCO, A., VIRAMONTES, R.: Aging of a Heat Resistant Alloy. In: 19th ASM Heat Treating Society Conference Proceedings Including Steel Heat Treating in the New Millennium Heat Treating. 2000, pp 1-7.

[3] Di VERNIERI CUPPARIA M.G., WISCHNOWSKI, F., TANAKA, D.K., SINATORA, A.: Correlation between microstructure and cavitation-erosion resistance of high-chromium cast steel - Preliminary results. Wear, 1999, Vol. 225-229, Part.1, pp. 517-522.

[4] HATTORI, S., KISHIMOTO, M.: Prediction of cavitation erosion on stainless steel components in centrifugal pumps. Wear. 2008, Vol. 265, pp. 1870-1874.

[5] NIEDERHOFER, P., HUTH, S., THEISEN, W.: Cavitation erosion and hydroabrasion resistance of cold work tool steels produced by powder metallurgy. Wear. 2015, Vol. 332-333, pp. 1059-1069.

[6] JAWORSKI, A., KRAWCZYK Ł., KUBIAK, K.: Turbine Housing Failure Due to Sigma Phase Precipitation and Embrittlement of Niobium-Stabilized Austenitic Steel Casting. Journal of Materials Engineering and Performance. 2020, Vol. 29, pp. 1535-1543. 